\title{
O CRITÉRIO DE JUSTIÇA E A DESCRITIVIDADE
}

\author{
THE CRITERION OF JUSTICE AND DESCRIPTIVITY
}

\author{
DENIS COITINHO ${ }^{1}$ \\ (Universidade do Vale do Rio dos Sinos, Brasil)
}

\begin{abstract}
RESUMO
O objetivo central desse artigo é investigar um relevante aspecto descritivista que parece estar contido no conceito de justiça para responder a uma crítica antirrealista e não-cognitivista a respeito da subjetividade dos juízos morais e de seu significado puramente prescritivo. Inicio salientando esse problema a partir de três argumentos estipulados por alguns não-cognitivistas de tradição analítica, a saber: o argumento da questão aberta, o argumento da relatividade e o argumento da estranheza. Posteriormente, buscarei apontar para a solução do problema fazendo referência à distinção entre os conceitos éticos abstratos (thin), como sendo puramente prescritivos, e os conceitos éticos densos (thick), como sendo prescritivos e descritivos. O próximo passo será analisar o conceito de justiça como um conceito ético thick. Usarei as concepções de justiça de John Rawls e Amartya Sen, buscando identificar um traço objetivo em razão da descrição de algo no mundo em conexão com a normatividade.
\end{abstract}

Palavras-chave: Justiça. Prescritivismo. Descritivismo. Conceitos Éticos Densos

\begin{abstract}
The main aim of this paper is to investigate an important descriptivist aspect that may be contained within the concept of justice to reply an anti-realist and non-cognitivist criticism concerning the subjectivity of the moral judgments and its purely prescriptive meaning. I will start by pointing out this problem from three arguments postulated by some non-cognitivists of the analytical tradition, namely: the open question argument, the argument from relativity, and the argument from queerness. Following this, I will try to point out the problem solution by referring to the distinction between thin ethics concepts, as purely prescriptive, and thick ethics concepts, as both prescriptive and descriptive. The next step will be to analyse the concept of justice as a thick ethics concept. I shall use the John Rawls's and Amartya Sen's conceptions of justice trying to identify a special objective trait in the description of something in the world in connection with normativity.
\end{abstract}

Keywords: Justice. Prescritivism. Descriptivism. Thick Ethics Concepts.

\section{Situando o problema}

Um dos principais problemas da filosofia moral e, me parece, um dos mais recorrentes, sempre foi o de querer saber a respeito do significado dos conceitos morais, tais como 'bom', 'mau', 'certo', errado', ‘justo', 'injusto, por exemplo, bem como a respeito de seu estatuto ontológico e a forma de como eles poderiam ser justificados. Teriam esses conceitos uma objetividade em razão de sua correspondência com alguma propriedade no mundo? Mas, como seriam essas propriedades como a 'bondade' ou a 'correção' e como poderíamos conhecê-las? Ou, alternativamente, eles só teriam um aspecto puramente 
prescritivo ou normativo e, assim, não descreveriam nada que pudesse contar como um fato no mundo e por conseguinte não poderiam ser tomados como verdadeiros ou falsos, sendo, dessa forma, considerados sem sentido, pois seriam vazios de conteúdo, implicando serem vistos como inteiramente subjetivos ou relativos por expressarem apenas as emoções dos agentes?

Uma resposta bem conhecida a esse problema foi dada por filósofos realistas, de forma que a objetividade dos conceitos e juízos morais seria consequência de sua correspondência com propriedades morais que existiriam independentemente da mente dos sujeitos e que se poderia conhecê-las por uma especial intuição intelectual. No início do século XX, autores de tradição analítica começaram a se contrapor a esse platonismo em razão de uma aversão à uma concepção metafísica do universo moral, questionando a existência mesma dessas propriedades morais e de como elas poderiam ser conhecidas, uma vez que não fariam parte da descrição natural do mundo e, mais especificamente, que seu significado teria somente um aspecto emocional, de forma que expressariam apenas os estados mentais dos sujeitos, não tendo conteúdo fatual. Creio que essa crítica não-cognitivista pode ser sintetizada em três argumentos que foram desenvolvidos nesse contexto e apresentados em diferentes momentos.

Começo com o argumento da questão aberta. Moore identificou que é impossível estabelecer uma definição do predicado "bom", pois esse predicado seria uma qualidade simples, indefinível e não analisável. Dessa forma, todas as descrições naturalistas de bem estariam erradas, uma vez que seria sempre possível perguntar se a propriedade que se usa para definir o bem seria realmente boa. Daqui segue a crítica aos filósofos que tentaram definir o bem por todas as outras propriedades que pertencem a todas as coisas que são boas, isto é, aos filósofos que cometeram a falácia naturalista (MOORE, 1903, I, 10 e 13). O que o argumento parece pressupor é o estabelecimento de uma forte distinção entre os juízos fatuais e os juízos normativos. Juízos fatuais apenas descreveriam fatos no mundo e poderiam ser tomados como verdadeiros quando correspondessem a esses fatos e falsos quando não se observasse essa correspondência. Quando se diz "Essa maça é vermelha" se faria uma descrição de um certo estado de coisas e se poderia verificar sua verdade pela existência de algo que seria uma maça e que seria vermelha. Diferentemente, os juízos morais seriam puramente prescritivos ou normativos em razão de não descreverem uma realidade no mundo. Assim, ao dizer que "mentir é errado" não se observaria nada no mundo que correspondesse a um estado de erro ou maldade de forma independente da estrutura mental do indivíduo. Wittgenstein, por exemplo, aponta para esse fenômeno ao distinguir entre juízos valorativos com sentido relativo e os que possuem um sentido absoluto. Quando se diz que "este homem 
é um bom pianista" apenas significaria que ele pode tocar certas peças de um certo grau de dificuldade com um certo grau de destreza. Há o uso da palavra "bom”, mas o seu sentido é relativo uma vez que apenas faz uma descrição, isto é, faz uma declaração de fatos a respeito da técnica de tocar piano. Por outro lado, ao dizer que "alguém está agindo mau" quando mente, não se observaria nenhuma descrição, mas uma tentativa de alcançar um sentido absoluto da palavra "bom", isto é, uma tentativa de estabelecer uma prescrição universal (WITTGENSTEIN, 1965, p. 04). Creio que o ponto importante dessa distinção seja a reinvindicação de que nenhum juízo normativo pode ser inferido ou deduzido de algum juízo puramente fatual, pois de puras descrições não se poderia inferir prescrições, uma vez que as descrições são sempre relativas enquanto as prescrições são absolutas ou, ao menos, se pretendem absolutas. $^{2}$

Mas, o que dizer dessa capacidade prescritiva do juízo moral? Esse juízo poderia expressar uma direção absoluta, isto é, uma norma que realmente obrigasse todos a segui-la? Uma vez que o juízo moral não estaria conectado a uma esfera fatual e sendo a linguagem limitada a um sentido natural, tal como é usada pela ciência, toda prescrição estaria limitada às convicções mais profundas dos agentes. Como dito por Ayer, a presença de um conceito ético em uma proposição não adicionaria nada ao conteúdo fatual e, assim, apenas expressaria a aprovação ou desaprovação do agente, isto é, apenas expressaria certos sentimentos morais (AYER, 1946, p. 107). ${ }^{3}$ Lembro de um interessante exemplo dado por Wittgenstein a esse respeito: se alguém pudesse escrever um livro de Ética como uma ciência do bem ele destruiria (em uma explosão) todos os outros livros que contivessem certas posições morais contrárias ao que estaria expresso nesse livro de Ética. Seu argumento é que a linguagem só pode comportar o sentido natural das palavras, expressando apenas fatos e a ética, ao contrário, tentaria ir além dessa restrição. Sua conclusão é que "Nenhum estado de coisas tem, em si mesmo, o que eu gostaria de chamar o poder coercitivo de um juiz absoluto" (WITTGENSTEIN, 1965, p. 07).

De forma similar, Mackie procurou apontar para esse problema da ausência de objetividade nos juízos morais com seu argumento da relatividade. O problema central estaria na dificuldade em tratar os juízos morais de primeira ordem como uma apreensão de verdades objetivas em razão de sua diversidade e até mesmo oposição. Esse desacordo moral pareceria refletir a adesão das pessoas a diferentes formas de vida, isto é, a diferentes concepções de bem, o que traria por consequência a identificação do caráter subjetivo dos juízos morais.

$\mathrm{O}$ argumento da relatividade pode ser apresentado da seguinte maneira: 
(i) A objetividade dos juízos morais implicaria em sua unidade;

(ii) Os juízos morais são relativos e até antitéticos;

(iii) Logo, os juízos morais não são objetivos (MACKIE, 1977, pp. 36-38).

Veja-se que Mackie está defendendo uma posição de ceticismo moral de segunda ordem, afirmando a não existência de valores objetivos. Como não existiriam valores morais com objetividade, ele nega que os elementos categoricamente imperativos sejam objetivamente válidos. Sua tese central é que, ao conceber os juízos morais, as pessoas pretendem assinalar para algo objetivamente prescritivo e que esta pressuposição é falsa (MACKIE, 1977, pp. 29-35). ${ }^{4}$ O que parece sustentar essa tese central em sua teoria do erro é o argumento da estranheza (queerness). Ele diz que se existissem valores objetivos deveriam existir entidades muito estranhas, inteiramente diferente de qualquer outra realidade no universo. Também, que se fossemos conscientes dessas propriedades deveria existir uma peculiar faculdade de percepção mental para reconhecê-las e isso é algo totalmente diferente de nossa forma comum de conhecer o mundo. A conclusão a que ele chega é que como não temos acesso a essas entidades e nem a essa intuição, os valores objetivos não existiriam (MACKIE, 1977, pp. 38-42).

Creio que uma possível forma de responder a essas críticas seja identificando um conceito moral que tenha objetividade em razão de sua descritividade, não sendo essa objetividade dependente da existência de entidades fora da estrutura mental do agente e nem dependente de uma intuição racional ao estilo platônico. Penso que o critério de justiça é um bom candidato para enfrentar tal desafio e isso por poder ser tomado como um conceito ético denso (thick) e que possui circunstâncias contextuais relevantes. No restante desse texto irei apresentar as principais características dos conceitos éticos thick e, posteriormente, procurarei analisar o conceito de justiça tal como é apresentado por John Rawls e Amartya Sen, buscando ressaltar em seu interior as características específicas de descritividade e contextualidade, aliados à normatividade, é claro, e de como isso não implicará em um problema inferencial e nem em uma posição cognitivista estrito senso.

\section{Conceitos éticos thick}

Para responder a essa acusação de que os juízos éticos não seriam objetivos em razão dos conceitos morais serem vazios de significado por não possuírem um componente descritivo, tal como o conceito "bom" sendo tomado como algo simples e indefinível, várias 
estratégias foram usadas. Uma delas foi tentar refutar o argumento de Moore a respeito do caráter indefinível de "bom", discordando da homonímia defendida entre "bom" no sentido moral e "bom" em um sentido não moral, reivindicando um conteúdo descritivo para esse conceito. $^{5}$ Outra estratégia utilizada foi identificar uma importante distinção no interior mesmo dos conceitos morais. Alguns conceitos morais, tais como "bom", "correto" e "dever", por exemplo, realmente seriam vazios de significado, uma vez que apenas contariam com uma característica puramente prescritiva. Mas o que dizer dos conceitos como "coragem", "humildade" ou "crueldade", por exemplo? Seria o mesmo caso ou esses conceitos morais vinculados a um padrão de comportamento virtuoso não contariam, também, com um importante aspecto descritivo?

Veja-se o caso de dizer que "Aquiles é corajoso". A virtude da coragem é claramente um padrão normativo, de forma que ela apontaria para um traço de caráter desejável por possibilitar uma vida bem sucedida, na forma de uma aprovação. Entretanto, o predicado "corajoso" parece também possuir um claro componente descritivo, uma vez que poderia ser entendido como uma descrição daquele que age de uma forma intermediária entre a temeridade e a covardia, ou como daquele que controla os seus medos de forma equilibrada. Da mesma forma, se dissermos que "Agamenon é cruel”, isso parece implicar em um modelo normativo ao apontar para um padrão comportamental não desejável, isto é, reprovável. Por outro lado, o predicado "cruel” parece ser passível de descrição, uma vez que poderia ser explicado como significando aquele que inflige deliberadamente dor e sofrimento aos outros. É importante ter em mente que o conteúdo descritivo é diferente nos conceitos de coragem e crueldade, embora sirvam igualmente como um padrão normativo de aprovação-reprovação. Iris Murdoch oferece uma resposta desse tipo ao estabelecer uma interessante distinção entre conceitos morais vazios (ou puros), como "bom" e conceitos morais mistos, como "liberdade". Para ela, a "liberdade" é um conceito misto (mixed concept), possuindo uma caraterística prescritiva, tal como "bom”, mas, além disso, possuiria, também, uma característica descritiva por ser um aspecto da virtude relacionada especificamente com a clarificação da visão e o domínio do impulso egoísta. Dessa forma, a "liberdade" é tomada como um padrão normativo desejável porque possibilitaria uma vida bem sucedida. Por outro lado, o conceito de "liberdade" parece possuir uma característica descritiva, significando o controle do impulso egoísta (Ver MURDOCH, 1970, p. 97). ${ }^{6}$

Os conceitos morais densos (thick) ou mistos parecem funcionar muito bem como um importante contraexemplo à ideia de que existiria uma integral dicotomia entre a esfera fatual 
e normativa. Se um conceito moral como "correto", por exemplo, não pode estar vinculado ao mundo dos fatos empíricos, então, se poderia deduzir que ele seria encontrado em um mundo puramente valorativo. Essa pretensa dicotomia parece ser abalada quando podemos fazer referência a um conceito moral que também se encontra relacionado a uma esfera contingente. Voltemos ao conceito moral de "crueldade". Como ele estaria referido a esse mundo fatual? Vejamos um interessante exemplo dado por Hilary Putnam a esse respeito. Suponhamos que alguém nos pergunte sobre o tipo de pessoa que é o professor do nosso filho e supondo que a resposta seja "Ele é muito cruel". O que isso significaria? Isso parece ser uma reprovação moral ao professor, isto é, parece implicar em uma crítica a ele tanto como professor quanto como pessoa. Por outro lado, "cruel” também parece possuir um significado descritivo. Por exemplo, quando historiadores escrevem que certo monarca foi "cruel", significando que ele deliberadamente infligiu dor e sofrimento a outras pessoas. Isso mostra que um conceito moral denso ignoraria a pretensa dicotomia entre fatos e valores ao incorporar ambos elementos, a saber, os elementos descritivos e os normativos (PUTNAM, 2002, pp. 34-35).

Uma linha de contra-argumentação apresentada pelos não-cognitivistas foi dizer que os conceitos éticos densos seriam inteiramente fatuais e não normativos. Hare, por exemplo, defendeu que o termo "rude" não é normativo a partir de um exemplo usado por Kohlberg: Um garoto diz algo ao seu vizinho em uma sala de aula. Este cospe na face do colega. A vítima, então, revida batendo no outro sem sair de sua cadeira. Tendo a professora notado o ocorrido, o garoto teria dito: "Professora, eu bati nele porque ele cuspiu na minha cara", ao que a professora teria respondido: "Isto não foi polido; isto foi rude". Com esse exemplo, Hare acredita que um ato satisfaça as condições descritivas por ser chamado "rude", sem estar comprometido, necessariamente, com uma avaliação normativa adversa (HARE, 1981, pp. 74-75). ${ }^{7}$

O ponto central que quero enfatizar nesse artigo é que quando nos confrontamos com situações que requerem uma avalição ética precisamos fazer referência às descrições dos motivos e do caráter dos agentes, por exemplo, para essa avaliação ser inteligível. Quando uma situação, um motivo ou uma ação é propriamente descrito, a decisão de se algo é bom ou ruim, certo ou errado justo ou injusto, parece seguir de uma forma natural em razão do contexto intersubjetivo que é referido nessa avaliação. Não é desejável nem eficiente dividir a vida humana entre um mundo dos fatos e um outro dos valores, como fazem os nãocognitivistas, uma vez que o mundo humano parece ser caracterizado pela estreita conexão dessas duas esferas, a descritiva e a normativa, para a realização de um plano racional e razoável de vida. A esse respeito, Putnam diz que: 


\begin{abstract}
Nosso mundo da vida, Murdoch está nos dizendo, não se divide claramente entre 'fatos' e 'valores'; vivemos em um mundo humano confuso em que vendo a realidade em todas suas nuances, vendo-a como George Eliot, ou Flaubert, ou Henry James, ou mesmo Murdoch a veem, pode, até certo ponto, nos ensinar a reconhecer isso e a fazer 'juízos de valor' apropriados ... (PUTNAM, 1992, p. 166).
\end{abstract}

Isso parece trazer por consequência que poderíamos alcançar a objetividade dos juízos morais nos valendo de conceitos éticos com densidade descritiva, tais como "coragem", "crueldade", "brutalidade", "gratidão", de forma a expressar uma unidade entre a esfera fatual e a esfera normativa. Além disso, esses conceitos éticos densos parecem possuir uma função especial se comparados aos conceitos morais abstratos: eles parecem servir de guias para ação, pois oferecem uma razão para a ação do agente. Esses conceitos éticos densos não funcionariam como puras prescrições, que indicariam apenas de forma abstrata o que seria correto e bom fazer. Antes, eles indicariam em primeira pessoa aquilo que seria desejável realizar por garantir uma vida bem sucedida. Tomemos a "coragem" como exemplo. Essa virtude é um traço permanente de caráter que é desejável em razão de possibilitar ao agente uma vida boa, que é desejável por indivíduos com certas características racionais, uma vez que essa virtude parece ser a razão necessária para o enfrentamento de diversos problemas. Ela não é uma regra descolada da ação do sujeito, mas funcionaria como um guia que orienta a ação do agente moral (Ver WILLIAMS, 1985, pp. 140-141).

Mas, e o conceito de justiça? Ele recairia na mesma classificação dos conceitos éticos densos? Teria uma parte descritiva, além da prescritiva e também funcionaria como um guia para ação? Ou, alternativamente, ele estaria mais imediatamente identificado como um conceito ético abstrato, sendo apenas uma prescrição, isto é, uma obrigação universal? Partirei da hipótese que o conceito de justiça é melhor interpretado como um conceito ético thick, que possui um aspecto descritivo além do normativo e que será determinado a partir de um contexto específico, não podendo ser confundido com uma norma moral vazia de significado fatual e que apenas expressaria as emoções dos agentes. Também, que sua objetividade não estará referida a nenhum objeto entendido como uma entidade metafísica independente da mente do sujeito moral e nem compreendida como aquilo que seria o verdadeiro em um sentido cognitivista tradicional. Para verificar essa hipótese, analisarei as concepções de justiça desenvolvidas por John Rawls e Amartya Sen a fim de identificar essas características thick. A escolha por essas teorias se deveu ao fato delas serem tomadas como referências fundamentais para a discussão contemporânea a respeito da justiça e por apresentarem 
diferentes modelos normativos para a sua construção.

\section{Justiça como equidade}

Comecemos com a concepção de justiça de John Rawls. A teoria da justiça como equidade (justice as fairness) busca estabelecer um critério normativo para determinar aquilo que é o justo, isto é, para aquilo que seria o correto de um ponto de vista público, uma vez que sua aplicação recai sobre a estrutura básica da sociedade, o que inclui as principais instituições políticas e econômicas. Sua estratégia geral é partir das convicções morais públicas compartilhadas em uma sociedade democrática, tais como as convicções de tolerância religiosa, recusa à perseguição e rejeição à escravidão para estabelecer princípios de justiça que descrevam essa concepção política de justiça que contará com os valores de liberdade, igualdade e bem comum a partir de uma escolha simétrica das partes na posição original e, então, testá-los por sua coerência com os juízos morais ponderados dos cidadãos e, também, por sua eficácia em garantir a estabilidade social e legitimidade política. Nas palavras de Rawls:

\footnotetext{
Justiça como equidade (justice as fairness) tenta fazer isso usando uma ideia organizadora fundamental em que todos os ideais e princípios possam estar sistematicamente conectados e relacionados. Essa ideia organizadora é a da sociedade como um sistema equitativo de cooperação social entre pessoas livres e iguais vistas como membros inteiramente cooperativos da sociedade considerando uma vida completa (RAWLS, 1996, p. 9).
}

Mas qual é mesmo o significado de justiça para Rawls? O que significa dizer que a justiça será identificada com a equidade, isto é, com fairness e que estará associada a uma ideia de contrato social? Creio que seja relevante fazer alguns esclarecimentos iniciais a respeito do escopo dessa teoria para evitar interpretar fairness como aquilo que seria o naturalmente justo, como o que apontaria para o critério normativo da igualdade em um sentido abrangente. ${ }^{8}$ Vejamos:

(i) A justiça está aplicada às práticas, isto é, ela é tomada apenas como uma virtude das instituições sociais e não como uma virtude das ações particulares das pessoas.

(ii) Opera com um sentido usual de justiça, o que significa apenas a eliminação de distinções arbitrárias e o estabelecimento de um equilíbrio entre as reivindicações conflitantes.

(iii) Formula princípios morais públicos que pertencem a um modelo liberal de justiça que, por sua vez, está conectado com as convicções políticas socialmente compartilhadas 
(RAWLS, 1958, pp. 164-165).

Essa concepção política de justiça pode ser vista na forma do estabelecimento de dois princípios: 1- cada pessoa participante em uma prática, ou afetada por ela, tem um direito igual a mais extensa liberdade compatível com a liberdade de todos e 2- desigualdades são arbitrárias a menos que seja razoável esperar que ela funcione para a vantagem de todos e possibilitando que as posições e cargos estejam abertos para todos os envolvidos dessa prática. Importante ressaltar que esses princípios seriam os escolhidos por pessoas que estivessem em uma situação de simetria. Esse aspecto normativo da teoria pode ser visto pelo importante papel que o véu da ignorância desempenha na posição original. ${ }^{9}$ Sendo assim, a justiça é compreendida como uma conexão entre as ideias de liberdade, igualdade e bem comum (RAWLS, 1958, pp. 165-166; 1971, p. 70/53 rev.). Mas, qual a característica central desses princípios? Eles seriam normas abstratas descoladas de toda a realidade fatual? Seriam normas morais absolutas deduzidas da razão de forma apriorística ou seriam normas morais descobertas pelos agentes ao observar algum fenômeno natural? A resposta a essas perguntas é negativa, uma vez que os princípios serão melhor interpretados como sendo regras de um jogo e que são estabelecidos sob certas circunstâncias que valerão como o contexto para a sua construção. ${ }^{10}$

Veja-se que a justiça está associada às práticas políticas e econômicas de uma sociedade democrática liberal contemporânea. Mas o que se entende mesmo por práticas? O termo 'prática' tem por significado qualquer forma de atividade especificada por um sistema de regras que definem, por exemplo, o emprego, a forma de propriedade, as penalidades, o valor dos impostos etc. Assim, jogos, rituais, julgamentos, mercados e sistemas de propriedades são práticas. Vejamos o caso de um jogo. As regras devem funcionar como parâmetros ou como normas que dão realidade ao próprio jogo e são sua condição de possibilidade. Por exemplo, as regras que determinam o movimento das peças do jogo de xadrez e de como estas peças podem ser tomadas constituem-se como o próprio jogo e, também, possibilitam que se joguem tais e tais partidas. O resultado será justo em uma partida de xadrez quando os jogadores agirem seguindo as regras. Os jogadores não reclamariam por estar em diferentes posições, como jogar com as peças brancas ou pretas ou ter certos poderes especificados pelas regras, como dar xeque, o que obriga o adversário a ter que sair dessa posição ou perder o jogo, o que seria um xeque mate. Podem considerar o resultado justo quando todos seguem as regras de forma especificada por eles próprios, uma vez que as regras do xadrez são uma criação humana e não uma determinação a priori absoluta. Da mesma 
forma, fairness pode ser compreendida como um conjunto de regras, os dois princípios de justiça, que orientam o jogo político e econômico dos cidadãos em uma sociedade democrática contemporânea. Tal qual num jogo de xadrez, se pode jogar com regras criadas pelos próprios participantes do jogo político e econômico e isso seria mais eficiente do que tentar estabelecer as regras a partir de um ponto de vista absoluto. Na justiça como equidade, as regras são construídas a partir de um ponto de vista social, isto é, são construídos na posição original sob o véu da ignorância. ${ }^{11}$

É importante ressaltar, também, que a teoria de Rawls se utiliza de um sentido usual de justiça, o que parece apontar apenas para a eliminação de distinções arbitrárias e o estabelecimento de um equilíbrio entre reivindicações conflitantes. Dessa maneira, fairness significaria somente "jogo limpo". Parece fundamental para a justiça o conceito de fairness que está relacionado ao direito entre as pessoas que estão cooperando ou competindo umas contra as outras. Aqui, fairness significa o dever que pessoas tomadas como livres e iguais têm de jogar limpo e isto implica, inicialmente, seguir as regras que elas mesmas estabeleceram visando sua convivência harmoniosa. Para Rawls:

Agora se os participantes em uma prática aceitam estas regras como justas (fair) e não têm nenhuma reclamação a fazer contra elas, surge um dever prima facie (e um correspondente direito prima facie) entre as partes em agir de acordo com a prática e exigir o seu cumprimento (RAWS, 1958, p. 179).

Outra importante característica dos princípios de justiça é que eles não são derivados de princípios a priori da razão ou mesmo conhecidos por uma intuição racional especial. Antes, eles são estabelecidos por certas circunstâncias bem específicas, a saber: pessoas que possuem interesses e necessidades e uma capacidade de agir cooperativamente ou moralmente, considerando a existência de uma escassez moderada de recursos. A ideia geral do procedimento é a de que se as pessoas estiverem em uma situação de simetria, elas escolherão os princípios que defendem a liberdade, a igualdade e o bem comum para o regramento de suas práticas políticas e econômicas em razão desses princípios melhor descreverem o seu próprio senso de justiça, que pode ser entendido como o compartilhamento de certas crenças morais-políticas que apontam para a aprovação de uma restrição aos interesses puramente privados. Os princípios de justiça, assim, funcionariam como restrições escolhidas pelos envolvidos que governariam os direitos e deveres em suas práticas comuns, os aceitando como uma limitação de seus direitos sobre outros (RAWLS, 1958, p. 174). ${ }^{12}$

Com isso em mãos, creio que se possa identificar o conceito de fairness como um 
conceito ético thick e não thin em razão dele possuir um importante aspecto descritivo a partir das próprias práticas da justiça e uma relevante situação contextual para sua determinação dada pelo procedimento de construção. Mas seria esse critério objetivo ou ele seria apenas o resultado das emoções dos agentes envolvidos na sua construção? E qual seria o seu significado? Ele poderia ser tomado como verdadeiro ou seria um critério puramente arbitrário? Para responder a essas questões farei uso de um ensaio de Rawls ainda não publicado, intitulado "A brief inquiry into nature and function of ethical theory", de 1946, ano em que Rawls inicia o seu doutorado em Princeton. ${ }^{13}$

Nesse ensaio, Rawls defende uma teoria que ele chama de "Utilitarismo Imperativo" e que serve para determinar quais atos se pode considerar como "correto" (right) ou "errado" (wrong) a partir do próprio uso que se faz dessas palavras morais por seus usuários. A ideia geral parece ser a de fazer deduções a partir de juízos morais reais de certo tipo de pessoas e testar essas deduções contra esses juízos morais. Ele defende aqui o seguinte princípio: “(...) dado duas ações de igual grau de otimização e igual frequência relativa, o ato que será mais apreciado será o que tiver maior ocorrência contextual" (RAWLS, 1946, p. 41). Essa ocorrência contextual significaria a frequência que tais ações seriam encontradas na vida social. Por exemplo: ser fiel, manter a promessa e falar a verdade seriam ações corretas em razão de apontarem para uma certa regularidade observada a partir de um ponto de vista social. O ponto central de Rawls é estabelecer uma contraposição ao emotivismo que diz que quando usamos as palavras "correto" e "errado" apenas se estaria expressando as próprias emoções do agente e que isto seria relativo a cada um. Ele diz que isso não é relevante para uma teoria moral que está preocupa no uso social de critérios morais. Por isso, Rawls não concorda com Moore e Ross em considerar os termos morais "correto", "errado" e "bom" como indefiníveis em razão da qualidade a que esses termos se refeririam serem indefiníveis. Para ele, isso é apenas um pseudo-problema, uma vez que ele defenderá que se pode definir um conceito moral como "correto" por um equivalente moral de como as pessoas compreendem o que seria o "correto". Toma isso como um fato linguístico, como um fato sobre a forma das pessoas usarem as palavras "correto", "errado", "bom" e assim por diante e não como um fato sobre a irredutibilidade de "correto" como uma qualidade objetiva de coisas (RAWLS, 1946, p. 23).

Outro ponto importante desse ensaio é a afirmação de que, como a linguagem moral é imperativa, não faz sentido requerer a verdade ou a falsidade dos juízos morais. Antes, seria preferível exigir a sua razoabilidade, sensatez ou racionalidade. Rawls diz que "assumindo 
que a teoria do utilitarismo imperativo seja correta, isto parece claro que declarações éticas não são verdadeiras ou falsas no mesmo sentido em que declarações fatuais o são" (RAWLS, 1946, p. 59). Não se diz, por exemplo, que o comando de fechar a porta seja falso quando a porta já está fechada, mas, ao contrário, se diz simplesmente que este comando não é sensato, que não é razoável. É o mesmo no caso moral. Quando se diz que se deve ser tolerante em tal e tal circunstância, não se deve perguntar se isso seria verdadeiro, mas se seria razoável. E a razoabilidade aqui implicaria naquilo em que todos os envolvidos poderiam aceitar, isto é, implicaria na aceitabilidade das regras pelos próprios agentes (Ver RAWLS, 1946, pp. 58-60; 1980, p. 554).

O que é importante destacar nesse ensaio que já apresenta o fio condutor do que viria a ser a teoria da justiça como equidade é que a objetividade defendida não contará com nenhuma entidade metafísica fora da estrutura mental do agente. Preferencialmente, estará associada com um procedimento para deliberar acertadamente sobre as regras que reproduzem um ponto de vista social. Também, que o significado de um termo moral como "correto" será determinado a partir do próprio uso que é feito pelos envolvidos, não sendo tomado como o que é verdadeiro, mas como aquilo que pode ser visto como razoável. Já no contexto da justiça como fairness, que fará uso de um modelo contratualista ao invés de utilitarista, dizer que uma ação é justa parece oportunizar, sim, um guia para ação do agente moral em sua comunidade política, não se tratando de uma proposição verdadeira. Mas, será que não se poderia objetar que o conceito de fairness seria puramente descritivo, não contando como uma norma e, assim, não poderia ser visto como um conceito ético? A isso podemos responder que além dos princípios descreverem o senso de justiça, eles são construídos a partir de uma situação de simetria das partes, isto é, as restrições impostas pelo véu da ignorância na posição original, e que essa posição equivale ao aspecto normativo da teoria que está conectado com os juízos morais convergentes. Importante ressaltar que Rawls também procurará superar a radical dicotomia entre os fatos e os valores.

\section{Abordagem das capacidades}

Passemos agora para a investigação a respeito da ideia de justiça que é formulada por Amartya Sen. Uma primeira característica importante que queremos destacar é que a sua abordagem das capacidades (capabilities approach) também parece buscar uma superação da usual dicotomia entre as esferas fatual e normativa. Já em seu livro On Ethics and Economics, Sen faz referência a essa dicotomia ao apontar que a economia moderna e contemporânea 
tentou excluir da análise econômica os juízos normativos, tais como os que tematizam a respeito de como se deveria viver ou quais seriam os nossos deveres morais, por exemplo, se concentrando hegemonicamente em procurar estabelecer juízos fatuais sobre um certo estado de coisas, por exemplo, o funcionamento dos mercados, a eficiência na produção e distribuição etc. Esse afastamento em relação à ética e sua aproximação com a engenharia, uma vez que suas investigações passaram a se ocupar primordialmente de questões de logística, teria enfraquecido a própria economia ao reduzir a sua análise a um estudo centrado apenas nos meios e sem mais nenhuma preocupação com os fins (SEN, 1988, pp. 2-10). ${ }^{14}$

Da mesma forma que os positivistas lógicos, os economistas teriam dividido a realidade entre uma esfera descritível e objetiva, a saber, a esfera das relações econômicas e outra puramente valorativa, a esfera dos juízos morais, que deveria ser totalmente excluída de sua investigação por não passar de uma projeção subjetiva dos desejos humanos. Para Sen, o grande problema da economia foi querer explicar o comportamento econômico de uma forma reducionista, o vendo como um comportamento racional, o que significaria ser tomado como uma escolha dos melhores meios para a realização de um fim ou como a maximização do autointeresse. Esse reducionismo se daria por uma pretensa equivalência entre o comportamento racional e o comportamento real. O problema corretamente identificado por Sen é que as pessoas parecem levar outras coisas em consideração para subsidiar as suas decisões e ações do que apenas a maximização do autointeresse e a escolha de certos meios para alcançar um fim. Pensar sobre a finalidade da vida humana é importante em um comportamento real, bem como a valorização das relações afetivas com as outras pessoas. Ser leal ou solidário, por exemplo, não é ser irracional, da mesma forma que não seria irracional cumprir deveres e perseguir a felicidade com foco no bem comum. Ao invés de um único motivo, existiria uma pluralidade de motivações para as ações humanas. Para Sen:

\footnotetext{
A mistura de comportamento egoísta e altruísta é uma das características importantes da lealdade ao grupo, e essa mistura pode ser vista em uma ampla variedade de associações de grupo, variando de relações de parentesco, comunidades aos sindicatos e grupos de pressão econômica (SEN, 1988, p. 20). ${ }^{15}$
}

Falar que o agente tem uma dupla motivação para a ação, isto é, que ele é motivado pelo autointeresse e que também é motivado por uma finalidade moral parece apontar claramente para a defesa de uma concepção de justiça que fará uso de fatos que podem ser descritos e, também, valores que podem ser defendidos. Vejamos em maior detalhamento como isso se dá. A concepção de justiça de Sen se pautará pelo argumento da qualidade de 
vida, de forma que a ação correta ou justa será aquela que melhora a qualidade de vida e a liberdade do agente. Mas, como a liberdade é compreendida nessa teoria? A liberdade é vista como as capacidades individuais para fazer coisas que uma pessoa racional e razoável valoriza. É possível perceber, então, que essa concepção de justiça estará relacionada com circunstâncias contingentes, não sendo uma norma moral vazia de significado fatual (SEN, 2000, pp. 70-74). ${ }^{16}$

Vejamos dois exemplos para poder compreender a importância das circunstâncias contingentes. Uma pessoa doente precisa de uma renda maior para tratar a sua doença, uma renda que uma pessoa sem essa doença não precisaria. Essa é uma circunstância de heterogeneidades pessoais. Outra circunstância contingente é a das diferenças de perspectivas relativas. Ser relativamente pobre em uma comunidade rica pode impedir que o indivíduo realize alguns funcionamentos (functionings) elementares, como participar da vida da comunidade, embora sua renda, em termos absolutos, possa ser maior do que o nível de renda no qual os membros de comunidades mais pobres podem realizar seus funcionamentos com grande êxito. ${ }^{17}$ Isso parece implicar que o foco da justiça estará centrado em como as pessoas conseguem viver de fato ou, dito de outro modo, o foco recairá na liberdade pessoal para realmente viver de um modo que se tem razão para valorar. É por isso que a noção de justiça estará circunscrita à noção das capacidades. Para Sen:

\footnotetext{
Venho procurando demonstrar já há algum tempo que, para muitos propósitos avaliatórios, o 'espaço' não é o das utilidades (como querem os 'welfaristas') nem o dos bens primários (como exigido por Rawls), mas o das liberdades substantivas as capacidades - para escolher uma vida que se tem razão para valorizar (SEN, 2000, p. 74).
}

Veja-se que o justo não será aquilo que maximiza o bem-estar e nem o que distribui igualmente os bens primários. Antes, a justiça seria alcançada quando se dá liberdade para o indivíduo exercer suas capacidades. A capacidade de um agente consiste nas combinações alternativas de funcionamentos cuja realização é possível para ele, sendo os funcionamentos aquilo que uma pessoa pode considerar valioso fazer ou ter. Por exemplo, a participação na vida da comunidade pode ser muito valiosa para um agente, enquanto estar nutrido pode ser muito mais importante para outro. Sendo assim, a capacidade parece ser um tipo de liberdade, isto é, uma liberdade substantiva de realizar combinações diferentes de funcionamentos. Por exemplo, uma pessoa rica que faz jejum possui um conjunto capacitório diferente do de uma pessoa muito pobre que está obrigada a passar fome, embora ambas tenham a mesma realização de funcionamento quanto a nutrir-se. Isso parece significar que o conjunto 
capacitório poderia ser tomado como a liberdade para realizar combinações alternativas de funcionamentos que podem ser escolhidos (SEN, 2000, pp. 74-76). Sen ressalta que o conceito de "funcionamentos" (functionings) tem raízes claramente aristotélicas, uma vez que reflete as várias coisas que uma pessoa pode considerar como valiosa fazer ou ter, como, por exemplo, ter honras ou bens ou mesmo fazer uma dada ação virtuosa. Isso remeterá a uma importante noção de florescimento humano. Assim, as capacidades e funcionamentos serão os critérios adequados para valorar a qualidade de vida e, dessa forma, possibilitar a vida boa. ${ }^{18}$

Essa abordagem das capacidades aponta para uma heterogeneidade de fatores que influenciam a vantagem individual, contrapondo-se a uma pretensa unidade dos critérios de utilidade e renda, por exemplo. O justo seria, então, um certo tipo de guia para ação dos agentes na forma de políticas públicas que favoreçam a realização de combinações de funcionamentos escolhidos, não sendo um critério moral puramente formal. Importante frisar que será necessário um consenso sobre os pesos que se utilizará em um processo avaliatório, o que vai exigir discussão pública e aceitação democrática. Aqui está claramente o aspecto normativo da concepção de justiça de Sen, uma vez que a escolha sobre os pesos usados na avalição moral será uma escolha social e não uma decisão de sujeitos isolados. Importante frisar que que a liberdade do agente é vista como as capacidades individuais para fazer coisas que uma pessoa racional e razoável valoriza e, por isso, o consenso de pessoas tomadas como racionais e razoáveis pode ser visto como um importante critério normativo para as políticas públicas (SEN, 2000, pp. 76-86). ${ }^{19}$

Mas que tipo de objetividade teríamos aqui nessa concepção de justiça? A objetividade pretendida por Sen parece não estar comprometida com uma concepção metafísica, na forma em que ela independeria da posição do sujeito que observa e que implicaria em algum tipo de correspondência entre o que é dito e o mundo externo. Antes, sua concepção de justiça parece estar centrada em uma concepção de objetividade posicional (positional objectivity), o que representa tomar a objetividade como um fenômeno dependente da posição do observador. Vejamos um esclarecedor exemplo dado por Sen: "Daqui da Terra, o Sol e a Lua parecem semelhantes em tamanho" (SEN, 2009, p. 156). A objetividade dessa declaração parece estar vinculada a posição do observador, por exemplo, que ele olha desde a Terra e não desde uma estação espacial, o que traz por consequência que outro observador na mesma posição deveria ser capaz de confirmar a declaração da semelhança de tamanho entre o Sol e a Lua. Nas palavras de Sen: “A objetividade posicional requer invariância interpessoal quando a posição observacional é fixa, e esse requisito é inteiramente compatível com variações de posições 
diferentes" (SEN, 2009, pp. 156-157).

Isso parece nos remeter a uma situação em que diferentes pessoas poderiam ocupar a mesma posição e validar a mesma observação feita. Por outro lado, a mesma pessoa poderia ocupar outras posições e realizar observações diferentes. Mas, qual é a importância dessa concepção para o que estamos discutindo? Essa compreensão de objetividade posicional parece mostrar que a observação não é um fenômeno puramente mental, subjetivo, mas que estaria conectado com alguma forma de realidade externa. Por exemplo, a percepção de um eclipse solar completo só seria possível em razão do Sol e da Lua terem o mesmo tamanho visível desde a Terra e isso parece ser independente da mente do observador no sentido da constituição mesma desse fenômeno. Por outro lado, essa compreensão não reivindica um ponto de vista absoluto, de lugar nenhum, de onde se faria uma observação totalizante do mundo externo (SEN, 2009, pp. 157-158).

Com isso em mãos, creio não ser difícil identificar as características thick da ideia de justiça que é defendida por Sen. A justiça é um critério normativo, pois defende a liberdade dos agentes para exercerem suas capacidades, isto é, a liberdade substantiva para escolher uma vida que se tem razão para valorar; entretanto, seu conteúdo descritivo é preenchido pelas diversas combinações alternativas de funcionamentos. Também, o justo não será determinado a partir de um ponto de vista absoluto, mas sua identificação se dará a partir de contextos muito específicos, servindo muito mais como um guia para a ação na forma de políticas públicas com foco na qualidade de vida dos agentes, preferencialmente do que visto como proposicionalmente verdadeiro. Mesmo sem contar com entidades metafísicas, o critério de justiça pode ser tomado como objetivo em razão da posição do observador em conexão com alguma forma de realidade externa, o que possibilita reconhecer tanto uma direção de ajuste mente-mundo quanto uma direção de ajuste mundo-mente.

\section{Considerações finais}

Essas características thick da ideia de justiça de Sen e também da concepção de justiça de Rawls parecem responder adequadamente às críticas não-cognitivistas a respeito do significado pretensamente subjetivo e emocional dos conceitos morais. Embora oriundas de tradições normativas diferentes, ambas defendem que os juízos morais e políticos não devem ser vistos como relativos e sem sentido, uma vez que possuem objetividade em razão do seu significado descritivo em conexão com a normatividade, objetividade essa que estará relacionada a um contexto específico e não a uma realidade imutável. Isso não implicará em 
uma posição cognitivista tradicional, é claro, uma vez que a objetividade desses juízos práticos não será assegurada por sua verdade, mas, antes, será possibilitada por sua razoabilidade e aceitação pública. Também, parece não haver um problema inferencial, em que se teria uma inferência inválida de regras prescritivas a partir de fatos brutos, uma vez que ambas as teorias parecem refutar a existência de uma dicotomia entre as esferas fatual e normativa. Dizer que regras não podem ser inferidas de fatos não é o mesmo que dizer que regras não podem estar relacionadas aos fatos.

Mas, seria esse argumento dos conceitos éticos thick suficiente para calar os nãocognitivistas de forma definitiva? Penso que apenas restaria a eles perguntar sobre o tipo de relação existente entre a descritividade e a prescritividade no interior mesmo do conceito de justiça, uma vez que não haveria uma dicotomia entre os universos dos fatos e dos valores. Como isso seria possível? Que tipo de relação seria essa? - poderiam questionar. Mas, ao meu ver, teriam que reconhecer que teorias morais que fazem uso de conceitos éticos thick, como é o caso do critério de justiça, não poderiam mais ser tomadas como teorias sem sentido em razão de fazerem uso de regras puramente prescritivas que expressariam somente os estados emocionais dos sujeitos. Tudo indica que teriam que reconhecer a objetividade dos padrões normativos usados por essas teorias. Pode não ser ainda uma resposta definitiva ao complexo problema do significado dos conceitos morais, mas já parece apontar para uma solução bastante promissora. 


\section{Notas:}

1 Professor do Programa de Pós-Graduação em Filosofia da Universidade do Vale do Rio dos Sinos (UNISINOS), São Leopoldo, R. S., Brasil. E-mail: deniscoitinhosilveira@gmail.com

${ }^{2}$ Em “A Lecture on Ethics”, Wittgenstein faz a seguinte afirmação: “(...) embora todos os juízos de valor relativo possam ser mostrados como mera declaração de fatos, nenhuma declaração de fato pode ser mesmo ou implicar um juízo de valor absoluto" (WITTGENSTEIN, 1965, p. 07). Essa mesma reivindicação é feita por Moore em sua formulação da falácia naturalista. Ele diz que um grande número de filósofos tentaram definir o bem pelas outras propriedades que pertencem a todas as coisas que são boas, isto é, tentaram identificar o bom com um predicado fatual, natural ou metafísico. Ver MOORE, 1903, I, 10. De forma semelhante, Hare dirá que que não se deve inferir um imperativo moral a partir de premissas puramente indicativas para não cair na "falácia descritivista". Veja-se a seguinte regra: "Nenhuma conclusão imperativa pode ser extraída validamente de um conjunto de premissas que não contenha pelo menos um imperativo". Ver HARE, 1952, pp. 17-31. Ver, também, HARE, 1963, pp. 7-29.

${ }^{3}$ Para Ayer, todo juízo moral é vazio de significado fatual. Por exemplo, se se diz que "Roubar dinheiro é errado", se produz uma sentença que não possui nenhum sentido fatual, e isso implica que ela não expressa nenhuma proposição que poderia ser tomada como verdadeira ou falsa. Nas palavras de Ayer: "Dizendo que certo tipo de ação é certa ou errada eu não estou fazendo nenhuma declaração fatual, nem mesmo uma declaração sobre meu próprio estado mental. Eu estou simplesmente expressando certos sentimentos morais. Ver AYER, 1946, p. 107.

${ }^{4}$ Essa posição de Mackie é conhecida como teoria do erro, estabelecendo que a pressuposição de objetividade nos juízos prescritivos implicaria na existência de entidades morais metafísicas e um tipo de intuição racional e que essa pressuposição é um erro. Ver MACKIE, 1977, pp. 48-49. De forma semelhante, Hare defende a não existência de propriedades prescritivas objetivas, no sentido em que objetivo significaria fatual. A despeito de algumas diferenças com a posição de Mackie, o prescritivismo de Hare também assume uma posição nãocognitivista. A esse respeito, ver HARE, 1981, pp. 85-86.

${ }^{5}$ Isso é o que faz Peter Geach ao estabelecer uma distinção entre dois tipos de adjetivos, a saber, adjetivos atributivos e adjetivos predicativos. Para ele, "bom" no sentido moral é sempre um adjetivo atributivo. Assim, quando dizemos que este é um "homem bom", o "bom” não apenas descreve um certo estado de coisas que faz um alguém ser um homem virtuoso, mas, também, implica em uma avaliação das diversas virtudes que devem ser pesadas e escolhidas. É diferente do exemplo "a faca é boa", em que "bom" seria tomado apenas como um adjetivo predicativo. Ver GEACH, 1956, pp. 64-73. Philippa Foot também irá tentar refutar o argumento da questão aberta de Moore ao defender uma posição naturalista de "bondade" a partir da distinção feita por Geach entre adjetivos atributivos e predicativos. Ver FOOT, 2001, pp. 2-3.

${ }^{6}$ Iris Murdoch faz uma distinção entre os conceitos éticos puros ou vazios, como "bom" (good), e os conceitos éticos mistos, tais como "liberdade", "crueldade", "humildade", que poderiam ser definidos. Ver MURDOCH, 1970, pp. 92-97. De forma similar, Anscombe apontará para a superioridade do termo 'injusto' sobre os termos de "moralmente correto" e "moralmente errado" em razão do justo estar identificado com uma ação que é descritiva. Ver ANSCOMBE, 1958, p. 14. Bernard Williams, por sua vez, usará os termos conceitos éticos thin (sem densidade) para "bom" e "correto", por exemplo, e conceitos éticos thick (densos) para "brutalidade", "coragem" e "gratidão". Para ele, esses conceitos éticos são mais densos (thicker), contando com uma parte descritiva, fatual, e com uma parte prescritiva, isto é, valorativa. Ver WILLIAMS, 1985, pp. 128-129. Putnam contará com a distinção já feita por Murdoch e Williams a respeito dos conceitos éticos abstratos, como "bom" e "correto", e os conceitos éticos mais descritivos ou menos abstratos, tais como "cruel", "irreverente", "egoísta", "decente" em seu empreendimento de superar a dicotomia entre fato e valor. Ver PUTNAM, 1992, pp. 165-167.

${ }^{7}$ De forma similar, Mackie defendeu que conceitos tal como "cruel" seriam apenas palavras que descreveriam fatos naturais, pois se elas tivessem um caráter normativo isso implicaria na existência de entidades metafísicas estranhas. O problema é de como se daria a conexão de um fato natural, como uma ação de crueldade - que causa dor por prazer - e o fato moral de que isso é errado (wrong)? Não seria necessário contar com uma entidade tal como "erro" (wrongness)? Ver MACKIE, 1977, p. 41.

${ }^{8}$ O termo fairness é traduzido para a língua portuguesa como "equidade". O problema dessa tradução é que o termo "equidade" possui uma história que remete geralmente a uma ideia de justiça natural, como aquilo que seria um corretor do direito positivo associado a uma virtude pessoal e isso não auxilia muito para esclarecer o 
projeto coerentista e contextualista de Rawls. Veja-se que no caso do pensamento moral de Aristóteles, "equidade" é a palavra usada para traduzir epieikeia, que é uma virtude possuída pelo homem virtuoso (equânime) para corrigir a generalidade da lei: "Essa é a natureza do equitativo: uma correção da lei quando ela é deficiente em razão de sua universalidade. E mesmo, é esse o motivo por que nem todas as coisas são determinadas pela lei: em torno de algumas é impossível legislar, de modo que se faz necessário um decreto" (ARISTÓTELES, 1999, V, 10, 1137 b 26-29). Não é esse o significado de fairness, que é melhor compreendida como jogo limpo ou como seguir as regras.

${ }^{9}$ Rawls esclarece que a posição original é a situação inicial apropriada que garante que o acordo fundamental alcançado seja justo (fair). A ideia é que pessoas racionais e razoáveis escolheriam esses dois princípios de justiça se o seu conhecimento de sua concepção de bem fosse restrita. As partes, que são representantes hipotéticos de todas pessoas racionais e razoáveis, apenas saberiam que desejam os bens primários (liberdades e direitos fundamentais, renda e riqueza, autoestima, por exemplo), mas não teriam conhecimento de suas próprias concepções de bem, bem como desconheceriam a sua situação particular na sociedade, como sua classe social, etnia, gênero etc. Nas palavras de Rawls: "Se exclui o conhecimento dessas contingências que permite aos indivíduos serem guiados por seus preconceitos. Dessa maneira, se chega ao véu da ignorância de uma forma natural. Este conceito não deve causar nenhuma dificuldade se tivermos em mente as restrições na argumentação que ele pretende expressar. A qualquer momento podemos entrar na posição original simplesmente seguindo um certo procedimento, a saber, argumentando por princípios de justiça de acordo com essas restrições (RAWLS, 1971, p. 19/17 rev.).

${ }^{10}$ Quero ressaltar que a justiça como equidade faz uso de uma concepção coerentista de justificação de forma que se terá a justificação dos princípios de justiça por sua coerência com os juízos morais ponderados em todos os níveis de generalidade, o que implica reconhecer que a justificação se dará pelo método de equilíbrio reflexivo. Para Rawls, a justificação independente da verdade deve conduzir a uma relação com a concepção moral inteira e de como ela se harmoniza com os juízos ponderados em equilíbrio reflexivo, uma vez que a "(...) justificação é uma questão de apoio mútuo de várias considerações, todas harmonizadas em conjunto em uma concepção coerente" (RAWLS, 1971, p. 579/507 rev.).

${ }^{11}$ É importante ter em mente que o ponto essencial é a especificação de um ponto de vista moral para o estabelecimento dos princípios que toma a sociedade e as pessoas como morais, se constituindo como um ponto de vista social. Esse ponto de vista é o da posição original, que é um procedimento de construção que deve ser testado por sua coerência e não um ponto de vista apriorístico da razão. Ver RAWLS, 1996, p. 23.

${ }^{12}$ No artigo "Kantian Constructivism in Moral Theory", ao fazer referência às duas circunstâncias da justiça, a objetiva (escassez moderada) e subjetiva (consenso moral mínimo), Rawls observa que os princípios de justiça devem servir como um ponto de vista compartilhado entre cidadãos com convicções abrangentes opostas, ponto de vista que deve ser imparcial e possuir um propósito prático, isto é, a estabilidade. Ver RAWLS, 1980, pp. $530-533$

${ }^{13}$ A tese de doutorado de Rawls, concluída em 1950, teve por objetivo fazer um estudo sobre os fundamentos do conhecimento ético e versou, principalmente, sobre o método de equilíbrio reflexivo e seus principais argumentos foram apresentados no artigo "Outline of a Decision Procedure for Ethics", publicado em 1951. A ideia central é mostrar os princípios implícitos nos juízos ponderados de juízes competentes a partir do seguinte método: (i) seleciona-se uma classe de juízos morais (a partir da moralidade de senso comum) e (ii) identifica-se se eles são coerentes com princípios razoáveis e justificáveis; se existe esta coerência, então, (iii) estes juízos morais são juízos ponderados e servem de critério justificacional para os princípios. Assim, passa-se a contar com princípios razoáveis e justificáveis para arbitrar o discenso moral. Os princípios são razoáveis, pois resultam de um mecanismo heurístico que deve expressar a razoabilidade. Os princípios que passam no teste de razoabilidade são aqueles que podem ser aceitos por homens razoáveis a partir de uma coerência com suas próprias intuições morais. Ver RAWLS, 1951, pp. 177-190. Ver, também, RAWLS, 1950, pp. 269-270; 282-318.

${ }^{14}$ Em On Ethics and Economics, Sen faz referência para as duas diferentes origens da economia. No período antigo e medieval, a economia estaria ligada à ética, como se pode ver no pensamento prático de Aristóteles, por exemplo, em que a economia, entendida como riqueza, estaria associada aos fins humanos, o que a inseria no âmbito da ética e da política. Já no Séc. XIX, a economia se aproxima do campo da engenharia com Leon Walras, uma vez que ela passa a se ocupar de questões de logística, centrada nos meios necessários para uma vida bem sucedida, estando relacionada, sobretudo, aos problemas de funcionamento do mercado. Ver SEN, 
1988, pp. 2-7. Ver, também, a interpretação que Hilary Putnam faz da abordagem das capacidades de Amartya Sen como um exemplo de superação da dicotomia entre fato e valor. Ver PUTNAM, 2002, pp. 46-64.

15 Adam Smith parece exercer uma forte influência nessa concepção de uma pluralidade de motivações para as ações humanas. É interessante notar que Sen não valida a tese usual que interpreta a teoria de Adam Smith como alicerçando a economia em uma única motivação, a saber, o autointeresse. Antes, como fica claro na obra The Theory of Moral Sentiments, os agentes econômicos também são movidos pela empatia (simpathy) com as outras pessoas, além de movidos pela prudência e autodomínio, e essa referência moral para ação é de fundamental importância para a obtenção da estabilidade econômica e social. Ver SMITH, 2002, pp. 11-17. Ver, também, SEN, 1988, pp. 22-28.

${ }^{16}$ De forma semelhante, Anscombe apontará para a superioridade do termo 'justo' e 'injusto' (unjust) em contraposição aos termos como 'moralmente correto' e 'moralmente errado' em razão de seu claro significado fatual. $\mathrm{O}$ homem justo, por exemplo, é aquele que habitualmente refuta cometer ou participar de qualquer ação injusta a partir de sua disposição para escolher acertadamente o traço comportamental que é desejável. O comportamento virtuoso é então construído a partir de uma performance das ações na forma de um desenvolvimento das capacidades dos agentes na sua finalidade de alcançar uma vida boa e isso significa o florescimento humano. Ver ANSCOMBE, 1958, pp. 15-19.

17 Sen faz referência para cinco circunstâncias contingentes que podem ser vistas como diferentes fontes de variação entre as rendas reais e as vantagens que se pode obter delas: (i) heterogeneidades pessoais, (ii) diversidades ambientais, (iii) variações no clima social, (iv) diferenças de perspectivas relativas, (v) distribuição na família. Isso mostra, por exemplo, que também as condições climáticas, sociais e familiares são importantes para a determinação do que será tomado como o justo. Ver SEN, 2000, pp. 70-72.

18 Importante ressaltar que essa concepção de florescimento humano como usada pela ética das virtudes é fortemente normativa, uma vez que é tomada como uma finalidade boa que todo agente deveria perseguir. E é por isso que as capacidades e funcionamentos serão os critérios adequados para a qualidade de vida, o que possibilitará uma vida boa. Ver SEN, 2000, p. 75. Ver, também, NUSSBAUM; SEN, 1993, pp. 1-6.

${ }^{19}$ Mais especificamente, Sen aponta sete características da escolha social, o que nos facilitará identificar o papel normativo central do critério de razoabilidade para sua teoria da justiça, a saber: (1) Focar nas comparações e não apenas no transcendental; (2) Reconhecer a pluralidade inescapável dos princípios concorrentes; (3) Permitir e facilitar o reexame; (4) Permitir soluções parciais; (5) Permitir a diversidade de interpretações e inputs; (6) Enfatizar os raciocínios e articulações precisos; (7) Especificar o papel do raciocínio público na escolha social. Ver SEN, 2009, pp. 106-111. Putnam faz um interessante comentário sobre a concepção das capacidades de Sen, a conectando com os funcionamentos valorosos, o que nos permite identificar a ligação de uma parte descritiva com a normativa em sua concepção de justiça. Para ele, a teoria de Sen tem por foco os funcionamentos que uma pessoa de certo tipo (racional e razoável) teria razões para valorar, tais como, autorrespeito, estar bem nutrido, participar da vida da comunidade, por exemplo. Ver PUTNAM, 2002, pp. 62-64. 


\section{Referências Bibliográficas:}

ANSCOMBE, G. E. M. "Modern Moral Philosophy". Philosophy. The Journal of the Royal Institute of Philosophy, Vol. 33, No. 124, 1958, pp. 1-19.

ARISTOTELES. Ethica Nicomachea. Ed. I. Bywater. Oxford: Oxford University Press, 1894 (Reimp. 1962).

. Nicomachean Ethics. Transl. Terence Irwin. 2 ed. Indianapolis: Hackett, 1999.

AYER, Alfred Jules. Language, Truth and Logic. 2 ed. London: Victor Gollancz Ltd, 1946.

FOOT, Philippa. Natural Goodness. Oxford: Oxford University Press, 2001.

GEACH, Peter. "Good and Evil". Analysis. Oxford, Vol. 17, 1956, pp. 33-42. Reprinted in: FOOT, P. (Ed.). Theories of Ethics. Oxford: Oxford University Press, 1967, pp. 64-73.

HARE, R. M. The Language of Morals. Oxford: Oxford University Press, 1952.

. Freedom and Reason. Oxford: Oxford University Press, 1963.

. Moral Thinking: Its Levels, Method, and Point. Oxford: Oxford University Press, 1981.

MACKIE, J. L. Ethics: Inventing Right and Wrong. London: Penguin Books, 1977.

MOORE, G. E. Principia Ethica. Cambridge: Cambridge University Press, 1903.

MURDOCH, Iris. The Sovereignty of Good. London: Routledge, 1970.

NUSSBAUM, Martha; SEN, Amartya. The Quality of Life. Oxford: Clarendon Press, 1993.

PUTNAM, Hilary. The Collapse of the Fact/Value Dichotomy. Cambridge, MA: Harvard University Press, 2002.

. Ethics without Ontology. Cambridge, MA: Harvard University Press, 2004.

RAWLS, John. "A Brief Inquiry into the Nature and Function of Ethical Theory". The Papers of John Rawls, Harvard University Archives, HUM 48 Box, Folder 3, 1946.

. "A Study on the Grounds of Ethical Knowledge: Considered with Reference to Judgments on the Moral Worth of Character". PhD. Dissertation. Princeton University, 1950.

. "Outline of a Decision Procedure for Ethics". Philosophical Review, 60, No. 2, 1951, pp. 177-197. 
. “Justice as Fairness". Philosophical Review, 67, No. 2, 1958, pp. 164-194.

1971. . A Theory of Justice. Original Edition. Cambridge, MA: Harvard University Press, 1999.

. A Theory of Justice. Revised Edition. Cambridge, MA: Harvard University Press, $\overline{\text { pp. 515-572. }}$

. "Kantian Constructivism in Moral Philosophy". Journal of Philosophy, 77, 1980, . Political Liberalism. New York: Columbia University Press, 1996.

SEN, Amartya. On Ethics and Economics. Oxford: Blackwell, 1988.

. Development as Freedom. New York: Alfred Knopf, 2000.

. The Idea of Justice. Cambridge, MA: Harvard University Press, 2009.

SMITH, Adam. The Theory of Moral Sentiments. Edited by Knud Haakonssen. Cambridge: Cambridge University Press, 2002.

WILLIAMS, Bernard. Ethics and the Limits of Philosophy. Cambridge, MA: Harvard University Press, 1985.

WITTGENSTEIN, Ludwig. “A Lecture on Ethics”. Philosophical Review, 74, 1965, pp. 3-12. 